\title{
Much to celebrate!
}

This year we have much to celebrate: BJPs is in its $50^{\text {th }}$ volume and there has been five years since it changed from Revista Brasileira de Ciências Farmacêuticas to Brazilian Journal of Pharmaceutical Sciences, an ISI indexed journal. More than this, if we go back to BJPS origins, the Anais de Farmácia e Odontologia da USP, there has been 75 years since it was firstly published, in 1939!

This can be considered a record for a Brazilian periodical. National journals, in general, have to face many, and sometimes huge, challenges to survive. They depend on federal agencies, state agencies and institutional support. Not rarely, the funds are scarce and competition is hard. So, the editors must be resilient and have a high dose of idealism. This has been true for BJPS' team. It is mandatory to emphasize the essential contribution of Professor Andrejus Korolkovas, who was the first Scientific Editor of both journals that preceded BJPS. Thanks to his expertise, belief and great enthusiasm, the journal has survived, continuing its journey towards improvements we can witness today!

It is worth to note that Professors that contribute to BJPS as editors and reviewers cannot be fully dedicated to the journal publishing process. Fortunately, we have been counting on their efforts and enthusiasm, besides their belief in the importance of the Journal as the main scientific vehicle for divulging Pharmaceutical Sciences developed in Brazil. Also, the expertise of national and foreign members of the Editorial Board has expressively contributed to distinguish the periodical, giving it more visibility.

Of course, besides editors and reviewers, we could do nothing without the participation and interest of the authors during those years. Although Brazilians are the majority, authors from other countries, especially from Asia and Latin America, have submitted their manuscripts. The increasing quality of the papers, in general, has made a significant difference in the improvement of BJPS quality and in its evolution.

On the basis of the foregoing considerations, we are optimistic about the perspectives of keeping consolidating the importance of BJPS to the Pharmaceutical Sciences field. We will address all our efforts and implement innovative ideas to succeed and increase the impact factor of the Journal. 


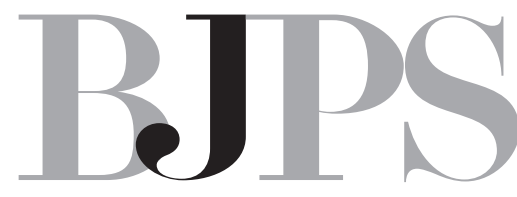

Brazilian Journal of Pharmaceutical Sciences

BRAZILIAN JOURNAL OF

PHARMACEUTICAL SCIENCES

The hard work of the Executive Editor and the support personnel has been fundamental for facing the challenges and implementing new actions toward BJPS evolution. On behalf of Leila Rangel de Carvalho Aranha, who is fully dedicated to make our dream of reaching the excellence comes true, I thank you all.

Hope from now on we have much more to celebrate!

Elizabeth Igne Ferreira

Scientific Editor 